\title{
Textos biográficos en el semanario ilustrado español El Artista (1835-1836): tipología y características generales ${ }^{*}$
}

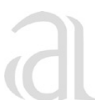 \\ Beatriz Gómez Baceiredo
}

Recibido: 27 de agosto de 2010 Aprobado: 30 de septiembre de 2010

\begin{abstract}
Resumen
La biografía, como género histórico-literario, se introduce en la prensa española de forma habitual en las revistas ilustradas del siglo XIX. Una de las primeras fue El Artista (1835-1836), donde lo biográfico adquiere un gran peso al ser el modo de dar a conocer y defender a los artistas nacionales. El estudio y clasificación de estos textos permite observar cómo la biografía empieza a amoldarse a las finalidades de la prensa pero manteniendo aún su naturaleza eminentemente literaria. Este estudio de los orígenes de uno de los géneros del periodismo literario con más permanencia en la prensa permitirá ir comprendiendo mejor sus características y peculiaridades en la actualidad.
\end{abstract}

Palabras clave: biografía, revistas ilustradas, necrológicas, periodismo literario.

Este artículo de investigación científica y tecnológica pertenece a la investigación Los textos biográficos en las cinco principales revistas ilustradas del siglo XIX. Aproximación a los orígenes de un género periodístico, realizada por la autora como parte de su tesis doctoral.

Profesora ayudante Facultad de Comunicación de la Universidad de Navarra, España. Doctora en Comunicación e Información Escrita y Periodismo literario. Correo electrónico: bgomezb@unav.es 


\title{
Biographic texts in the "el artista" spanish weekly journal (1835-1836): typology and general characteristics
}

\begin{abstract}
Biographies as a literary and historical genre were first introduced in the Spanish press by illustrated magazines of the 19th century. One of the pioneers was El Artista (1835-1836), where biography gained importance as a way to defend and give relevance to national artists. A proper look into those first texts offers a typology. That classification enables to comprehend how biographies started then to adapt to the aims of Journalism but, at the same time, still kept its primarily literary essence. This research into the origins of one of the most permanent literary genres yields a better understanding of its present-day main features.
\end{abstract}

Key words: biography, illustrated magazines, obituaries, literary journalism. 


\section{Introducción}

Decía Virginia Woolf que escribir biografías es endiablado (Edel, 1984, p. 17) ${ }^{1}$, pero pocos géneros literarios ${ }^{2}$ se han cultivado y estudiado más y desde hace más tiempo ${ }^{3}$. Escribir biografías en prensa tampoco parece tarea fácil, pero en cambio apenas se han estudiado como género. A este respecto, sigue siendo cierto lo que en 1998 afirmaban Sánchez y López Pan: "Entre nosotros, Ángel Benito, Martínez Albertos, Casasús y Gomis han descrito a grandes rasgos el origen de los géneros periodísticos; pero está pendiente un estudio detallado y minucioso sobre cada género en particular" (p. 17). Sólo López Hidalgo (1998) ha hecho un breve repaso histórico de las necrológicas, pero no se ha hecho aún de los géneros biográficos en general..

De hecho, esa falta de monografías obliga a no centrarse tanto en un género como en aquellos textos periodísticos en los que lo biográfico resulta nuclear. Por eso -y no fundamentalmente por los debates teóricos al respecto-, en este artículo se hace un uso no técnico de la noción de género ${ }^{4}$ o, en todo caso, el uso técnico que se emplea aquí estaría más ajustado a la noción de

\footnotetext{
"'Yes', said Virginia Woolf 'writing lives is the devil'".

2 Según Winslow, la biografía se define mayoritariamente como la "historia de la vida de una persona particular" y se considera una rama de la literatura. Sin embargo, autores como John Garraty la adscriben a la historia y otros muchos han investigado las relaciones de la biografía con esta ciencia. También se ha estudiado desde otros muchos campos, como la sociología, el feminismo, la antropología, el psicoanálisis o la teología por lo que en la actualidad se puede considerar este género como "interdisciplinar" o transversal. (Winslow, 1995, p. 9; Tolles, 1996, pp. 71-83; Rosendo, 1999, pp. 90-93).

3 No hay unanimidad a la hora de situar el momento en que apareció el término "biografía". Por ejemplo, María Antonia Álvarez (1990, p. 425) lo sitúa en 1721, mientras que Demetrio Estébanez Calderón (1996, p. 101) y Donald Winslow (1995, p. 8) lo hacen en 1683. Sin embargo, sí la hay en que es uno de los géneros literarios que se han cultivado siempre, en mayor o menor medida, a lo largo de la historia. Edel (1984, p. 24 y 36) incluso remonta su nacimiento a algunos textos del Antiguo Testamento. Rosendo (1999) realiza un breve repaso histórico de la biografía en el ámbito latino y anglosajón (pp. 79-96).

4 Al respecto, véase el repaso que hacen Sánchez y López Pan (1998) de las distintas tipologías genéricas planteadas por los principales teóricos del momento: Martínez Albertos, Núñez Ladevèze, Bernal y Chillón, Gomis y Sánchez (pp.15-35). Conviene consultar también las recientes ideas de Vidal (2005) sobre la innovación en los géneros.
}

macrogénero, cuya naturaleza es englobar otros géneros 5 .

En este artículo se propone comenzar el estudio del género biográfico en la prensa española desde su origen, es decir, desde el momento que saltó de los libros de Historia y de las novelas a los papeles periódicos. Como es lógico suponer, los primeros periodistas que quisieron redactar un texto biográfico no tuvieron que inventar un género, sino que adaptaron a la prensa el género literario biografía. De este modo, los textos biográficos fueron adquiriendo características periodísticas y puliendo o desechando las literarias hasta configurar un género periodístico por sí mismo. Para entender cómo se llega hasta ahí, es decir, cómo son en la actualidad los géneros biográficos en la prensa española, parece muy útil observar esa transformación, ver qué características tenían esos textos desde el principio para así poder entender mejor lo actual a través de lo que ha pervivido o se ha modificado.

En concreto, en esta investigación se propone observar cuáles y cómo fueron esos primeros pasos en la revista ilustrada El Artista, una de las publicaciones que comenzó a incluir este tipo de textos en sus páginas de manera habitual (Gómez, 2006). Para ello, se tratará de contextualizar la prensa ilustrada y esa publicación en el ambiente social y periodístico del momento para así entender mejor los textos encontrados en el análisis de contenido y poder a su vez establecer una tipología.

\section{Metodología}

Para realizar este estudio de los textos biográficos publicados en El Artista, se ha optado por una metodología que ha permitido a la vez un estudio profundo y exhaustivo.

En primer lugar, para dar contexto al análisis cuantitativo y cualitativo de los textos biográficos, se han revisado los principales manuales sobre prensa española en el siglo XIX, así como los

\footnotetext{
Por eso se utilizarán en este artículo términos como "textos biográficos" o "textos de contenido biográfico" y, aunque a veces aparezca "género biográfico", siempre se hará en este sentido (Genette, 1998, pp. 183-233).
} 
capítulos y monografías sobre revistas ilustradas. También ha sido necesario acudir a los manuales sobre Historia de España para entender las circunstancias políticas y legales que condicionaron la aparición de esta revista.

En segundo lugar, se han analizado todos los números de la revista, página a página, a través de una revisión hemerográfica de las microfichas ubicadas en la Biblioteca Nacional Española. Este archivo presenta algunas lagunas -apenas una decena de páginas- debido a problemas de conservación, por lo que no se puede asegurar la compleción de los datos. Este análisis detallado era necesario ya que, como se verá, la biografía no estaba aún asentada como género en estas publicaciones y por tanto no eran fiables las secciones o los títulos para dirimir si el contenido de los textos era biográfico o no. A partir de este análisis de contenido, se ha elaborado una tabla con los rasgos formales y de puesta en página que permiten ubicar y describir el texto. En concreto, se recoge: número, título, antetítulo o subtítulo, autor, sección, extensión, posición dentro de la revista, si era un texto seriado y si venía acompañado de alguna ilustración o retrato.

En tercer lugar, tras la lectura y el estudio de estos textos, se propone una tipología según el tipo de personaje que aparece biografiado y se describen las características generales de ese tipo de textos.

\section{Las revistas ilustradas españolas}

Las revistas aparecieron en los años treinta del siglo XIX español con la romántica pretensión de formar al pueblo ${ }^{6}$. Entre las que vieron entonces la luz destacaron, como explican Sánchez Aranda y Barrera (1992), las revistas ilustradas, que imitaban modelos ingleses y franceses y "eran una expresión o manifestación de la burguesía, que se mostraba como modelo al resto de la población" (pp. 130-131).

6 Estas publicaciones se pueden catalogar en tres grupos, según estos autores: de evasión, ideológicas y "magazines" con un interés social y altruista de elevar el nivel cultural de los menos dotados. (Sánchez Aranda y Barrera, 1992, p. 130).
Sus principales características eran: una esmerada presentación externa (en tamaño folio, bien impresas ya que estaban pensadas para encuadernar y coleccionarse), la inclusión de ilustraciones y láminas intercaladas en el texto, la presencia de colaboradores ilustres y la identificación "-extraña en la prensa diaria- entre propietario, editor y redactor, aunque no fuesen la misma persona, si bien el editor era la pieza clave" (Sánchez Aranda y Barrera, 1992, p. 131).

En cuanto al contenido, en una de estas revistas, en El Museo Universal, se explicaba que las "publicaciones ilustradas, á manera de universal enciclopedia" se dedican a "enunciar ó suscitar memorias, consignando lo mas interesante en sucesos y recuerdos, en ciencias, artes, Historia, Literatura". Se escogía por tanto "entre la inmensa variedad de asuntos que mas ó menos conducen á la ilustracion general, y que moralizando é instruyendo despejan la inteligencia y avivan la imaginacion" ("Autógrafos de hombres célebres", El Museo Universal, 29 de enero de 1865).

Además de por la influencia foránea, la aparición de estas revistas se explica por la tradición de publicaciones didácticas y enciclopédicas en España durante el siglo XVIII. En esa época, como señala Seoane (1977), existía una interesante prensa en dos versiones: "La de los (Diarios noticiosos y de avisos) y una prensa vehículo de la Ilustración o, mejor aún, de comunicación entre ilustrados, cuyo interés radicaba en la divulgación de conocimientos, en proporcionar la posibilidad de (estar al día) con poco esfuerzo" (pp. 19-20) . Como en toda época de censura rígida -y el absolutismo lo era- la prensa se debía refugiar en

\footnotetext{
La prensa en aquella época era, en general, formativa porque los liberales consideraban que la libertad de imprenta era un medio para educar a los ciudadanos, para formar una "opinión" favorable al nuevo régimen. En este sentido, es significativo, tal y como señala Seoane (1977), que en la Constitución de 1812, el artículo 371, el relativo a la libertad de imprenta, esté colocado en el apartado de Instrucción Pública: "Como nada contribuye más directamente a la ilustración y adelanto general de las naciones y a la conservación de su independencia [dice el discurso preliminar de la Constitución| que la libertad de publicar todas las ideas y pensamientos que puedan ser útiles y beneficiosos a los súbditos de un Estado, la libertad de imprenta, verdadero vehículo de las luces, debe formar parte de la ley fundamental de la Monarquía si los españoles desean sinceramente ser libres y dichosos". (p. 36).
} 
los estudios científicos, literarios o filosóficos, de ahí el auge de estas publicaciones (Seoane, 1977, p. 23).

Pero una vez que Fernando VII juró la Constitución, en 1820, la prensa resurgió súbitamente durante los tres años de régimen liberal. Casi todos eran diarios políticos, "apasionadamente encuadrados en las distintas tendencias ideológicas que van a surgir durante estos agitados años" (Seoane, 1977, p. 271), pero también de corta vida. Los asuntos científicos y literarios desaparecieron casi por completo, ya que la prensa se fue al extremo opuesto, a la politización total, signo característico "de las épocas de crisis, de lucha" (Seoane, 1977, p. 119).

Una excepción a esta regla, aunque sin abandonar la lucha, (en este caso, literaria), fue la revista El Europeo. Este Periódico de Ciencias, Artes y Literatura -como rezaba su subtítulo- apareció en Barcelona, en noviembre de 1823, de la mano de un grupo de jóvenes catalanes y extranjeros ${ }^{8}$. Su propósito, según Alborg (1980), era defender la libertad artística y llevar la paz a los criterios enfrentados, con una perspectiva cosmopolita ( $p$. 87). Fue además, según Seoane (1977), la primera revista romántica española, dentro del romanticismo tradicionalista devoto de Walter Scott. Sin embargo, su corta vida -desapareció el 24 de abril de 1824- le impidió cumplir su sueño de enraizar el romanticismo en España (pp. 195-196).

Pese a que no se puede enlazar con la tradición de las revistas ilustradas, ya que es más bien una revista literaria, comparte con El Artista la defensa del romanticismo (aunque para esta última es un ingrediente más, no su objetivo principal), y fue a su vez pionera en su orientación apolítica, de espaldas a la actualidad (Guarner, 1953, pp. XII-XIII).

Durante la Década Ominosa (1823-1833), frente a la casi inexistencia de prensa en la Península, los españoles emigrados llegaron a publicar hasta siete periódicos entre 1824 y 1829, algunos de ellos con vocación formativa ${ }^{9}$. Pero pese a la

8 Eran Buenaventura Carlos Aribau y Ramón López Soler, y tres extranjeros: el inglés Ernest Cook y los italianos Luigi Monteggia y Fiorenzo Galli, emigrados liberales. (Guarner, 1953, pp. XII-XIII). ${ }^{9}$ Los más destacados: El Español Constitucional, El Telescopio, sequía de publicaciones, dentro de España empiezan a aparecer y a formarse las figuras y tendencias que van a dominar la escena literaria y periodística. En estos años surge el grupo de los jóvenes escritores (Bretón, Espronceda, Mesonero, Larra), que se reúne en la tertulia de "El Parnasillo", presidida por Carnerero. Muchos eran discípulos de Lista, por lo que respetaban los principios del clasicismo y compartían la ambición de restaurar las letras españolas, algunos de ellos desde el Periodismo (Alborg, 1980, p. 56).

Y así se llega a 1835. Tras la muerte del Rey, se estrena régimen político y se ensayan fórmulas para hacer compatible la libertad de imprenta con el orden público. En medio de esta situación, El Artista comienza el periodismo formativo, ilustrado (aunque a partir de ahora ilustrado se refiere al uso de imágenes, ilustraciones) que se prolongará hasta bien entrado el siglo XX.

A pesar de que esta revista sólo se publicó durante un año, desempeñó un papel fundamental en su época y abrió las puertas a un modo de hacer Periodismo que perdurará, con gran éxito, durante todo el siglo XIX.

Aunque, siguiendo las directrices de El Europeo, prefirió vivir de espaldas a la vida política, ésta determinó en gran medida su orientación, y más aún lo hicieron las circunstancias sociales, por lo que merece la pena detenerse un instante para resumir a grandes rasgos la situación política, social y periodística del país.

\section{Contexto político y periodístico}

En 1835, cuando aparece El Artista, España estaba en pleno proceso de adaptación a una nueva realidad política y cultural, y también en plena guerra. Tras la muerte de Fernando VII (1833), estalla el conflicto carlista en forma de una guerra civil que durará siete años. Originado por el problema dinástico que surgió al ser la heredera directa una mujer, este conflicto aparecerá de forma intermitente durante todo el siglo y será un elemento perturbador en la política y muy cruento para la población (Comellas, 1988, pp. 130-140).

Ocios de Españoles Emigrados y el Correo Literario y Político de Londres (Alborg, 1980, pp. 97-99) 
Como explica Seoane (1983), para conseguir legitimidad y atraer las mayores simpatías del pueblo, los gobiernos isabelinos se vieron obligados "a una progresiva liberalización para crear una opinión favorable a la Reina niña". Así, una nueva amnistía, sin las limitaciones de la otorgada durante la enfermedad del Rey, permitió que regresaran todos los exiliados, muchos de ellos "con un importante bagaje de conocimientos y experiencias periodísticas adquiridas en Londres o París" y que iban a reflejar en los periódicos que fundaron o en los que colaboraron (p.139).

El primer gobierno de María Cristina, la reina gobernadora, fue el de Cea Bermúdez. La especie de "despotismo ilustrado" que quiso imponer a través de su Manifiesto -con reformas administrativas, pero no políticas, ya que mantenía la monarquía "en todo su vigor y pureza"- no convenció a los liberales, y mucho menos a los carlistas, por lo que la reina sustituyó a Cea por Martínez de la Rosa.

Este, por medio del Estatuto Real de 1834 (una "carta otorgada", no una constitución), trató de conciliar lo antiguo con lo nuevo, y, pese a ser considerado "raquítico" por los liberales, por la escasez de reformas que ofrecía, al menos cumplió la función de cerrar definitivamente el absolutismo monárquico (Comellas, 1988, pp. 140-146).

En agosto de 1836 la "sargentada" de la Granja acabó con el régimen del Estatuto y la Reina se vio obligada a restablecer la Constitución de 1812. Apenas un año después, sin embargo, las Cortes promulgaron una nueva Carta Magna ${ }^{10}$ bajo el gobierno de Calatrava, que abrió una nueva etapa.

La prensa, durante este corto espacio de tiempo, había aumentado notoriamente. Según Seoane (1983), en 1834 había 36 diarios en Madrid; en 1836, antes de la "sargentada", 120, entre ellos más de cuarenta diarios y 49 boletines de provincias. Pese a que estas cifras tienen un valor muy relativo (dado que muchos periódicos suprimidos aparecían de nuevo bajo otro nombre), muestran la vorágine que se vivió en la prensa tras

${ }^{10}$ En concreto en junio de 1837 . Una Constitución "progresista en la forma, moderada en el fondo", según decía el periodista Andrés Borrego (Comellas, 1988, p. 161). el fin de absolutismo, aunque, eso sí, la mayoría de estas publicaciones eran efímeras (pp. 142-145).

La ley sobre prensa más relevante en esos momentos es el decreto del 4 de enero de 1834 , bajo el gobierno de Cea Bermúdez, completado por el reglamento del 10 de junio. Este decreto establecía que: "No necesitan licencia ni censura previas los periódicos que traten de materias literarias y científicas y sí los que traten de política o religión" (Seoane, 1983, p. 141).

Por su parte, "el reglamento del 10 de junio crea la figura del editor responsable y la fianza o depósito previo (de 20.000 reales en Madrid), ambas inspiradas en la legislación francesa" (Seoane, 1983, p. 142). De ese depósito se descontaban las multas en caso de infracción y tenía que ser repuesto inmediatamente, si no, se cerraba la publicación ${ }^{12}$.

Esta legislación es clave para las revistas ya que, el único modo de evitar la licencia y la censura era absteniéndose de publicar contenidos políticos. Por eso, pese a que las revistas ilustradas están inspiradas por otras inglesas y francesas -O son copia de ellas-, en las españolas siempre se evitarán, en la medida de lo posible, los temas políticos $^{13}$.

\section{El Artista}

El semanario El Artista es la primera revista ilustrada que, según Seoane (1983), "alza la bandera de la literatura y el arte en medio del hiperpolítico

11 Sánchez Aranda y Barrera (1992) lo explican así: "Se entendía por editor responsable aquella persona que respondía de lo publicado y a la cual se le exigían unas condiciones mínimas (fundamentalmente el pago de una determinada cantidad de impuestos) que no estaban al alcance de todas las personas ni de todos los políticos, sino sólo de los grandes" (p. 133).

12 Para burlar la censura, los periodistas debían usar su ingenio y recurrir a la ironía o los sobreentendidos, aunque no siempre funcionaba, como lo demuestra el famoso último número de El Siglo, impreso totalmente en blanco, de la primera a la última página, salvo la cabecera. Seoane, 1983, p. 143).

13 Las revistas inglesas, que se toman en muchos casos como referente, nacen un contexto totalmente distinto. En plena lucha por la rebaja de las tasas -lo que se llamó el movimiento de los intimbrados, iniciado en 1831 con el Poor Man's Guardian- las sociedades altruistas, de acuerdo con el Gobierno, promovieron unos semanarios de conocimientos útiles para demostrar que se podía imprimir prensa barata y popular sin violar la ley. El referente clásico de este tipo de publicaciones es el Penny Magazine (Sánchez Aranda, 1994, p. 45). 
panorama" (p. 165) que se vivía entonces. Debe su título, orientación y hasta el tipo de letra a la revista L'Artiste, publicada entre 1831 y 1838 por Achille Ricourt, aunque nunca la cita, a pesar de que a veces llega "al plagio de artículos y grabados" (p. 166).

Su edición era muy bella y lujosa con ilustraciones en litografía, (normalmente dos en cada número), "sobre todo retratos que acompañaban a las biografías de escritores y artistas antiguos o contemporáneos y reproducciones de monumentos artísticos" (Seoane, 1983, p. 166). Cada número constaba de doce páginas en papel vitela ${ }^{14}$ dedicadas tanto a la crítica e información literarias como a la literatura de creación. Tenía un tamaño de $27^{\prime} 5 \times 20^{\prime} 5$ centímetros con $21 \times 15^{\prime} 5$ centímetros de caja ${ }^{15}$. El texto iba siempre a dos columnas y para establecer una pequeña separación entre los diversos asuntos tratados se anteponían denominaciones genéricas a los títulos de los artículos: Biografía, Literatura, Pintura, etc. Su precio era caro: 30 reales al mes, mientras que los diarios costaban 20 (Simón Díaz, 1946, pp. 7-8).

Apareció por primera vez el 4 de enero de 1835, de la mano de dos veinteañeros, el escritor Eugenio de Ochoa ${ }^{16}$ y el pintor Federico de Madrazo. José Simón Díaz (1946), en su magnífico índice analítico sobre El Artista, resume así la trayectoria y los papeles que desempeñaron los dos protagonistas de la revista:

Eugenio de Ochoa había regresado poco antes [de la fundación de la revista] de París, en donde asistió a la Escuela Central de Artes y Oficios durante cinco años, pensionado por Fernando VII. Cuidaba especialmente de la parte literaria e insertó numerosos trabajos suyos (poesías, cuentos, biografías, etc). Su posición frente al influjo francés es interesantísima, pues en él se armonizan una fervorosa admiración por las nuevas ideas y por los escritores principales del país vecino (Víctor Hugo, al que tradujo

14 Según la RAE, el papel vitela es "el liso y sin grano, de gran calidad, cuya superficie permite la reproducción detallada de los dibujos más finos".

15 Se entiende por caja o mancha de una publicación el espacio de la página susceptible de ser impreso.

16 Randolph (1996) escribió una biografía sobre este personaje. en parte; Delavigne, a quien tuvo excesivo aprecio, etc.); con la sistemática repulsa para todo intento de reemplazar las obras literarias, los bailes, las modas o las costumbres españolas en general por las de aquella procedencia (...).

Federico de Madrazo tuvo a su cargo la dirección artística y compuso gran parte de las ilustraciones. Su familia cooperó a la empresa, y así vemos con frecuencia el nombre de don José, el pintor de cámara que estudia las obras maestras del Museo del Prado, y, sobre todo, el de Pedro, alumno a la sazón de la Universidad de Valladolid, lo mismo que Zorrilla y que Morán, los cuales remitieron, sin duda por su conducto, algunas composiciones (p. 8).

Como destaca Alborg (1980), Ochoa había trabajado con Lista, y Miñano, de los que había aprendido mucho sobre Periodismo y el arte de escribir. Este dato es fundamental para entender su postura moderada y razonada ante el romanticismo que, según Alborg permanece alejada "de las fantasmagorías en que algunos la cifraban" (p. 170).

Porque, como se dijo al hablar de El Europeo, la defensa del romanticismo no era el objetivo principal de esta revista. Desde el primer número, en el prospecto o presentación de intenciones de la publicación, dejaron claro que lo que pretendían era defender las bellas artes (sobre todo españolas), hacer notar su presencia en una época totalmente colapsada por las zozobras políticas. Así comienzan su justificación.

Estraño parecerá á algunos que en una época como la presente, mientras resuena por todas partes el estruendo de las armas, y están todos los ánimos ocupados en especulaciones políticas, haya quien crea atraer la atencion del público, hablando no de intereses materiales, ni de guerras, ni de protocolos, sino de bellas artes, de artistas contemporáneos y de grandes hombres sepultados entre el polvo de las tumbas (El Artista, 5 de enero de 1835).

El tono de la revista es, según Simón Díaz (1946), "de una gran altura y discreción". Casi no publican esas anécdotas y curiosidades con que 
los periodistas remediaban la escasez de originales y "muy pocas veces se reproducen textos de otras revistas, lo que contrasta con lo que se hizo con sus trabajos, que volveremos a encontrarlos más de una vez en sucesivos índices. Tampoco abundan las polémicas, y cuando surgen se desarrollan con exquisita corrección" (pp. 8-9).

El arte de la pintura mereció una atención poco frecuente. Publicaron "análisis y descripciones de las obras maestras conservadas en el Museo del Prado, biografías y estudios de los grandes artistas antiguos (Rafael, Miguel Ángel, Velázquez) y modernos (Goya), notas técnicas, interesantes paralelos, etc.". El grabado, sobre todo en madera, interesaba mucho a los autores, aunque "la mejor estampa de su valía artística la dejaron en su propia obra: las estampas que ilustraban la revista, no menos merecedoras de admiración que el texto. Son 96 y entre ellas hay 30 retratos" Simón Díaz, 1946, p. 11).

Además de estas láminas, en sus páginas se pueden encontrar poesías (aquí se publicó por primera vez La Canción del Pirata, de Espronceda), anuncios de estrenos, obras nuevas publicadas, cuentos, críticas teatrales, extractos de novelas, canciones y, por supuesto, biografías, como ya se ha mencionado.

En el índice por materias de Simón Díaz (1946) se encuentra la entrada "Biografías", con sólo 14 artículos, y "Necrologías", con dos. Sin embargo, esto no entra en absoluto en contradicción con los 48 artículos que se rescatan en este análisis, ya que Simón Díaz se guía por las denominaciones genéricas expresas y no parece que haya entrado al contenido de los textos.

Lo biográfico no era un contenido más, ya que, según Randolph (1966) (y como se deduce del prospecto), uno de los principales objetivos de esta revista era "sacar del olvido o impedir que se olvidaran los hombres del pasado y contemporáneos, que habían contribuido a la grandeza artística del país" (pp. 21-22). Por su parte, Simón Díaz (1946) destaca, entre las secciones principales de El Artista, "una serie de biografías compuestas por diferentes escritores que se agrupa bajo la denominación común de 'Galería de Ingenios Contemporáneos'. En ella figuran literatos, pinto- res, actores, etc., e incluso colaboradores de la revista" (p. 12). Esto se estudiará detenidamente a continuación.

\section{Textos biográficos}

Una vez que se ha contextualizado y descrito la revista, cabe presentar los textos de contenido biográfico. Como se dijo en la metodología, no se puede asegurar haber recogido todos los textos publicados por cuestiones de calidad de conservación, aunque sí una muestra altamente significativa.

Por otro lado, el hecho de que no se haya limitado el análisis a aquellos artículos publicados bajo el marbete "Biografía" o similares, sino que se haya recogido todos los de contenido biográfico, hace que la muestra sea muy amplia y heterogénea. Pero ya que se están observando los primeros pasos de lo biográfico en la prensa, se tendrán que seguir sus huellas por cualquier parte de la revista, aunque luego tal vez no lleven a lo más significativo. Para ello se verá primero cómo clasifican los textos en la revista y después se tratará de explicar o, más bien, racionalizar, esa clasificación.

En El Artista, como se puede ver en la Tabla 1 , se han encontrado 48 textos con contenido biográfico, repartidos en 37 números. La mayoría de los números, por tanto, contiene un solo texto biográfico; en concreto, sólo ocho incluyen dos y, lo más significativo, en el último número se publican cuatro.

De este dato se deducen, al menos, dos cosas: la primera, que el cierre de la revista, como ya es sabido, fue precipitado y no voluntario, ya que contaban -o al menos esperaban- con que podían continuar. Y la segunda, que estos textos biográficos estaban, como vulgarmente se conoce en términos periodísticos, "en nevera", es decir, archivados a la espera de ser publicados en cualquier número. Se puede entender, entonces, que los contenidos biográficos en esta revista -al menos la mayoría- no estaban a merced de las contingencias de la actualidad, sino que eran "imperecederos", se podían publicar indistintamente en un número u otro. 
La mayoría vienen firmados y, sobre todo en el primer tomo ${ }^{17}$, el autor que más se repite es Eugenio de Ochoa, director y alma de la revista, junto a Eugenio de Madrazo. En los otros encontramos también a Pedro de Madrazo, J. Colom y Colom y varias abreviaturas: S. M., A., V. C., O J. N. G.

Prácticamente todos los textos biográficos se ubican en primera página (22) o en el interior de la revista (24) y sólo dos cierran el número. Estas posiciones son lógicas si se tiene en cuenta que la extensión media de estos textos es de dos páginas, aproximadamente, lo que indica que -de acuerdo con la tónica general de la revista- se trata de contenidos relevantes, que no se utilizan para rellenar huecos.

Sólo tres están seriados ${ }^{18}$, es decir, repartidos en dos o más números. Curiosamente, se trata de dos artículos sobre pintores, Velázquez y Leonardo da Vinci, donde se repasa con detalle su trayectoria vital y artística. En este último, es curioso que los números en los que se publica no sean correlativos, sino que salten del 13 al 19 del tomo segundo.

En el aspecto gráfico, pese a que sólo se han encontrado referencias a 23 retratos ${ }^{19}$, se sabe por los índices de Simón Díaz (1946) que hay $30^{20}$, la mayoría a página completa o en media página. Las dos ilustraciones a las que se hace referencia en los textos corresponden a cuadros de Zurbarán y Murillo.

17 Recordemos que las revistas ilustradas se publicaban dando por hecho su encuadernación, normalmente por años, aunque en este caso no coincide exactamente. Por eso la numeración de las páginas no empieza con cada número, sino que es seguida desde enero hasta diciembre.

18 En estos artículos sólo se han contabilizado aquellas partes que tienen contenido biográfico. En el caso de Leonardo da Vinci, por ejemplo, que está dividido en tres números, sólo se clasifican dos (El Artista, tomo II, $\mathrm{N}^{\circ} 13$ ). Por otro lado, hay que tener en cuenta que hay artículos que se anuncian seriados luego nunca se retoman. Los artículos de El Artista citados en el cuerpo del texto no se incluirán en la bibliografía al estar bien identificados en la tabla 1.

19 Se considera retrato las ilustraciones de la cara o el busto del personaje, no a lo que se conoce como retratos literarios (prosopografía y etopeya). También las reproducciones del rostro en estatuas o monumentos funerarios.

20 En el primer número de El Artista, se observa una anotación a mano del catalogador de la Biblioteca Nacional en donde se lee: "Faltan todas las litografías (excepto la de Velázquez)". Por eso, al recoger el número de retratos, sólo se ha podido contar aquellos a los que se hace mención expresa en el texto.
Para saber cómo denominaban los propios escritores a los textos de contenido biográfico, hay que fijarse en los antetítulos y subtítulos y en los nombres de las secciones ${ }^{21}$. Esto permitirá hacerse una idea del contenido, que se describirá a continuación.

En El Artista se preocupan mucho por clasificar los textos, tanto por género como por contenido. Optan sólo por antetítulos, normalmente genéricos, como "Biografía" (4), "Noticias de" (4) o "Necrología" (2). Sin embargo, el más numeroso "Galería de ingenios [o injenios] contemporáneos]" (18) hace referencia al contenido.

Podría ser entonces que se tratara de un título de sección, pero los ejemplos de esta "Galería" están incluidos a su vez dentro de una sección mayor, que normalmente alude al contenido. Así, hay secciones de "Literatura" (11), "Bellas Artes" (9), "Historia del Arte" (2) o "Nobles artes" (1).

Es importante aclarar, para explicar por qué detenerse tanto en los antetítulos y secciones, que el término "Biografía" se presenta desde el principio muy indefinido por lo que habrá que dar todos los datos posibles para intentar aclararlo. Por ejemplo, de los cuatro textos de El Artista con el antetítulo de "Biografía", tres son de pintores fallecidos (dos de ellos se incluyen en la sección "Bellas Artes") mientras que el tercero es la biografía y crítica artística de una actriz contemporánea.

Visto esto, se ha optado por considerar estas secciones y descripciones genéricas como algo orientativo a la hora de mostrar el contenido biográfico de las revistas, y se ha preferido hacer personalmente una clasificación según dos criterios básicos: contenido y forma.

\section{Tipología}

Los textos de contenido biográfico encontrados en El Artista se pueden clasificar en tres grupos, que en este estudio se presentarán según un orden temporal: del pasado al presente y de menor a mayor actualidad. Estos grupos son: a) el de los grandes genios, tanto españoles como extran -

\footnotetext{
Se considera que se abre una sección cuando se destaca su título con tipografía muy destacada y se mantiene al menos en tres números.
} 
jeros; b) las necrológicas y c) el de los artistas contemporáneos.

\subsection{Grandes genios}

Dentro de este grupo se puede diferenciar, por un lado, los que se consideran grandes genios españoles, que personalizarían la gloria e identidad del país y, por otro, los grandes políticos y artistas extranjeros, que también se proponen como ejemplo.

Entre los españoles, el grupo más numeroso, Ochoa elige a Velázquez, una de las figuras más representativas de las artes nacionales, como primer texto biográfico de su revista. Y lo presenta así:

Al proponernos publicar sucesivamente los retratos y biografías de nuestros grandes ingenios, creimos no poder empezar mas dignamente esta venerable colección, que con el retrato y biografía del pintor mas esclarecido que ha producido nuestra pátria, tan fecunda como la que mas en eminentes artistas (El Artista, $\mathrm{N}^{\circ} 1$, tomo 1).

Como se desprende de estas palabras y, como ya se vio al hablar de los objetivos de esta publicación, desde El Artista quieren subrayar la riqueza artística del país, demostrar que aun en tiempos de revoluciones políticas, el arte sigue vivo, aunque sea en condiciones precarias ${ }^{22}$. Pero esta defensa de la cultura la hacen desde una posición muy clara, la del romanticismo sosegado, ese que defiende el pasado nacional y alaba el genio creador, pero siempre lejos de tenebrismos y fantasmas.

Por eso buscan personajes que representen el "orgullo nacional" ("Juan de Herrera", El Artista, $\mathrm{N}^{\circ} 3$ tomo II ), la diferencia con otros países ${ }^{23}$, como el propio Velázquez, Juan de Herrera, Cal-

22 Para mostrar esa precariedad comparan la vida de los artistas del pasado con la situación de esos momentos: "Hemos creido deber dar estos prolijos detalles |sueldo de Lope de Vega y patrimoniol porque ademas del interes que á nuestro parecer ha de inspirar todo lo que hace relacion á este grande ingenio, contribuyen á hacernos formar una idea exacta del aprecio que entonces se hacia en España de la literatura y de los literatos". ("Lope de Vega", El Artista, No 14, tomo II).

23 "iY una nacion que posee entre sus poetas nacionales al autor de Las Armas de la hermosura, de Las tres justicias en una, del Pintor de su deshonra va á estudiar en Racine y en Corneille los secretos del arte trágico!". ("Calderón", El Artista, N 5, tomo I). derón, Juan de Villanueva o Lope de Vega. La vida artística de estos personajes se plasma en textos bastante largos, titulados con los nombres de los personajes; no se incluyen en ninguna sección ni llevan distintivo de género.

La elección de estos personajes es en sí misma una defensa del romanticismo, ya que Calderón y Lope de Vega se consideraban precursores o referentes de este movimiento. Pero también pueden ser más explícitos ${ }^{24}$, sobre todo a la hora de criticar el clasicismo.

Así, se encuentran críticas que van, desde la claridad meridiana: "Porque digan lo que digan los hombres de limitado entendimiento, un imitador no será nunca mas que un imitador y por consiguiente un hombre mediano, lo cual en lenguaje artístico equivale como todo el mundo sabe a malo" ("Velázquez", El Artista, $\mathrm{N}^{\circ}$ 1, tomo I). A la descalificación: "Dicen no obstante los clasiquistas que es muy fácil hacer comedias sin reglas (...). Pues haganlas y se lo agradeceremos mucho y no les llamaremos autores narcótico-soporíferos como los llamamos" ("Calderón", El Artista, N 5, tomo I). Y hasta al insulto: "Estos críticos se parecen no poco á ciertos animales proscritos por la ley de Mahoma para quienes tiene un atractivo inefable todo objeto nauseabundo" ("Calderón", El Artista, $N^{\circ}$ 5, tomo I).

Lejos de la defensa del romanticismo, pero dentro de este grupo de genios españoles, se encuentran cuatro textos con el antetítulo "Noticias de". Se puede deducir que emplean el término "noticia" porque se trata de textos más cortos, concisos y basados sobre todo en datos. No hay crítica o comentario a las obras, y parece que su única intención es sacar del olvido a determinados personajes de nuestro país ${ }^{25}$.

El ejemplo más claro está en "Noticias de poetas cómicos sevillanos". En este artículo hablan de nueve autores (siete hombres y dos mujeres)

\footnotetext{
24 Hay que recordar que en esta revista publicó Espronceda, además de su célebre "Canción del pirata", el famoso artículo "El pastor clasiquino", cuyo final dice así: "Y Clasiquino, paso tras paso, se recogió a su majada, tenaz en su empeño de seguir hecho borrego mientras le durare la vida". ("El pastor Clasiquino", El Artista, $\mathrm{N}^{\circ} 21$, tomo I).

25 La excepción es "Noticia sobre la vida y obras de Henrick Wergeland, poeta noruego", (El Artista, $\mathrm{N}^{\circ}$ 6, tomo II).
} 
sevillanos de los siglos XVI y XVII. Son textos "curriculares", centrados en la vida profesional. Los personajes van uno detrás de otro, no hay relación entre ellos, ni tampoco comparaciones o similitudes. Se dice de cada uno lo que el autor ha podido recopilar o puede saber: "Muchas comedias compondria esta Señora pero á nosotros no han llegado, que yo sepa, nada mas que las dos intituladas: Conde Partinuplés. Valor, agravio y mujer" (El Artista, $\mathrm{N}^{\circ}$ 2, tomo III).

Los textos sobre grandes personalidades extranjeras se caracterizan porque se encuentran en las secciones de "Historia", "Bellas Artes" o similares y porque, pese a incluir datos de la vida, el peso recae algo más en el comentario de su obra. Un ejemplo paradigmático es el de Leonardo Da Vinci, un artículo muy documentado, erudito y extenso (El Artista, $N^{\circ} 13$, tomo II).

Pero, en este caso, lo importante está en la excepción, ya que en la sección de "Historia" se encuentra el primer texto biográfico escrito en paralelo sobre dos grandes estadistas: Washington y Bolívar. En el artículo se va comparando la vida pública de uno y otro, así como sus cualidades morales, para, en realidad, hacer un panegírico de Bolívar, algo que en ningún momento se intenta ocultar: "Bolivar era tan superior á Washington como la cordillera de los Andes á la cadena de las Montañas Azules" (El Artista, N 13, tomo II). Es, de nuevo, un modo de exaltar el romanticismo, ya que contrapone la apasionada lucha por la libertad del impetuoso Bolívar con el racionalismo frío y falto de ingenio de Washington.

\subsection{Necrológicas}

También sobre personajes fallecidos, pero más recientemente, encontramos en El Artista cuatro textos, dos de ellos con el título expreso de "Necrología". Este tipo de artículos aparecerá en todas las revistas ilustradas de la época (Gómez, 2006), y el factor común es que ofrecen datos biográficos o aspectos de la personalidad de una persona que ha fallecido. Si la muerte es más o menos reciente, o si se trata de un personaje público o privado, dependerá de cada revista.

En la que estamos considerando, se caracterizan por dar la noticia de la muerte al principio del artículo. Además, en dos de ellas el autor del artículo, al conocer al fallecido, trata de expresar su dolor, algo que se hará muy común años más tarde. Así se hace en uno de ellos:

En la noche del viernes 13 del corriente espiró D. José María Cruz en los brazos de una familia virtuosa y desgraciada que ha estado sosteniendo de doce años á esta parte. Si aun las personas indiferentes no han podido saber la prematura muerte de este jóven apreciable sin sentimiento ¿̇uán grande no nos habrá cabido en ella á los que, habiendo tratado y estimado al recien fallecido, hemos podido apreciar sus talentos, su aplicación y mas de todo sus grandes virtudes de que su alma estaba adornada? Vamos, sin embargo en medio de nuestro dolor á dar una sucinta noticia de la vida artística de este malhadado amigo (...).

[Y acaba] Hombre que amaba á su segunda madre como absolutamente propia, á sus segundos hermanos como si otros no hubiera conocido, y en fin, que constituido en verdadero padre de todos, apartó siempre de sí la idea del matrimonio por no separarse de familia tan querida. Virtudes de esta especie, oscuras y modestas, son tan raras en el dia que merecen la publicidad y el sincero homenage que á la par de su desconsolada familia les tributamos con nuestras lágrimas ("Necrología", El Artista, № 8, tomo III)

Las otras dos son sobre personajes públicos y presentan un tono más "aséptico". Se centran casi exclusivamente en su carrera artística y apenas ofrecen referencias sobre su carácter:

Anunciamos con mucho sentimiento la muerte del famoso Bartolomé Pinelli, pintor y grabador romano. La extraordinaria fecundidad de su ingenio ha hecho su nombre célebre en Europa, y su temprana muerte será sinceramente sentida por todos los amantes de lo bello y aun mas por los innumerables admiradores y apasionados de sus obras. ("Bartolomé Pinelli. Necrología", El Artista, $\mathrm{N}^{\circ} 19$, tomo I).

\subsection{Artistas contemporáneos}

Este grupo, el más numeroso de todos, gira fundamentalmente en torno a la sección "Galería 
de Ingenios Contemporáneos", que aparece en el número 14 del primer tomo. En la introducción de este artículo, dedicado a Francisco Martínez de la Rosa, se pueden observar las claves de estos textos:

Siempre es empresa arriesgada escribir vidas de personajes contemporáneos; pero cuando estos se hallan colocados en tan alta posicion social como el autor de la Conjuracion de Venecia, la dificultad es entonces capaz de arredar á cualquier escritor, por muy timorato que sea. Es en efecto difícil, muy difícil que prescinda el historiador de sus simpatias personales, de todas las consideraciones de odio ó de afecto que influyen en el juicio que forma de los hombres y de las cosas; y aun cuando lo logre, es mas dificil todavia, si se trata de personajes y sucesos contemporáneos, que le hagan todos la justicia de creer que para juzgarlos no ha escuchado mas que las inspiraciones de su conciencia. Los editores del Artista, y el autor de este artículo en particular, se lisonjean sin embargo de que el público no los comprenderá en el número de aquellos que, por espíritu de partido ó por consideraciones puramente personales, derraman á manos llenas la alabanza ó el vituperio: su carácter de escritores noveles y la independencia propia de sus pocos años, los ponen á cubierto de que se les confunda con aquellos que antes dije, á quienes sus antecedentes políticos ó su posicion social obligan á desfigurar la verdad y aun tal vez sus propias opiniones.

Pero no se crea, por la gravedad de este exordio, que me propongo hablar del Sr. Martínez de la Rosa en las diferentes fases de su vida política; ni es ese mi objeto, ni puede serlo jamás cuando trate de personajes contemporáneos. Como escritor, como poeta dramático, pertenece el autor de Moraima á la jurisdiccion del Artista; como diputado en 1814, como secretario de estado en 1822 y como presidente del consejo de Ministros en 1835 pertenece el Excmo. Sr. Don Francisco Martínez de la Rosa á la jurisdiccion de la Historia.

Nació este poeta en Granada en el año 1789 (...) "Don Francisco Martínez de la Rosa", El Artista, N 14, tomo I).
Lo más destacado de esta introducción es, sin duda, el recelo que muestran al abordar a personajes vivos, por el temor a que les acusen de parcialidad. Esta sección, sin embargo, era inevitable si, como se puede leer en el primer número, uno de los objetivos de la revista era demostrar la valía artística de ciertos personajes del momento (por supuesto, siempre dentro de la órbita del romanticismo).

Para evitar los recelos, dejan claro que sólo se van a ocupar de la faceta artística de los personajes, esquivando sobre todo la política (no hay que olvidar que en este momento está vigente el decreto de 1834, que exime de censura y licencias a las publicaciones que no traten de política ni de religión) y, por supuesto, tampoco entrarán en asuntos personales ${ }^{26}$.

Fuera de la "Galería de Ingenios Contemporáneos" continúan con la defensa del romanticismo, aunque, en una muestra de la tan buscada imparcialidad, incluyen también a personajes de formación o tendencias clasicistas, aunque eso sí, sin poder evitar decir lo equivocados que estaban: "Toda esta época de la vida literaria del Sr. Saavedra fue esclusivamente dedicada al culto del mas riguroso clasicismo, y asi todas sus composiciones de entonces carecen del carácter verdaderamente español y original que tan justa celebridad le han grangeado sus últimas producciones" ("Don Angel de Saavedra", El Artista, № 15, tomo I).

Un artículo muy destacado es la "Biografía" de "Doña Concepción Rodríguez". Se incluye dentro de este grupo porque se trata de una artista contemporánea (actriz) y porque se centra casi por entero en criticar su trabajo y sus aptitudes. Es relevante porque se utiliza por primera vez el calificativo de "Biografía" y, a este respecto, hay que destacar que lo que diferencia a este texto de los otros es su escrupulosa secuencia cronológica al mostrar cómo evolucionó su talento y su fama. También es importante porque es el primer artículo centrado por entero en una mujer "Biografía. Doña Concepcion Rodriguez", El Artista, $\mathrm{N}^{\circ} 17$, tomo II).

\footnotetext{
${ }^{26}$ Y, sorprendentemente, apelan a su juventud para asegurar su independencia, obviando que, precisamente, los ímpetus de la juventud no suelen ser de gran ayuda en estos casos.
} 


\section{Conclusiones}

Tras el estudio de El Artista en su contexto social y periodístico se ha comprobado que, por su propósito editorial y estilo y por ser modelo de las revistas ilustradas, resulta idónea para estudiar los textos biográficos publicados en sus páginas. Del análisis y clasificación de estos textos se puede concluir:

1. La "Biografía", como sección o nombre de género no está en absoluto asentada. Los textos se clasifican por contenido, por la profesión del biografiado, no por la forma.

2. Los textos biográficos son relevantes dentro de la revista: son largos y ocupan la primera o primeras páginas.

3. Prima la finalidad instructiva sobre la informativa. La actualidad no es un criterio de publicación, salvo, en escasa medida, en las necrológicas.
4. Los textos biográficos, se pueden clasificar según su finalidad en: grandes genios de la historia, necrológicas y artistas contemporáneos.

Genios de la historia: insignes figuras nacionales de las artes (Velázquez, Calderón, Lope). Es un modo de defender el romanticismo como movimiento nacional.

Necrológicas: aunque haya transcurrido tiempo, la noticia de la muerte se coloca en primer lugar. Centradas en la carrera profesional, aunque expresan dolor y cercanía.

Artistas contemporáneos: textos más numerosos. Quieren mostrar con ellos el valor de la cultura española y por eso vencen sus reticencias expresas a hablar de personas vivas. Se centran en la vida artística, nunca en la política ni mucho menos en la personal. Procuran no caer en los extremos de la alabanza gratuita o el vituperio.

Tabla 1. Textos biográficos publicados en El artista

\begin{tabular}{|c|c|c|c|c|c|c|c|c|c|}
\hline Número & Título & Ante/subtítulo & Autor & Sección & Extensión & Posición & Seriada & Retrato & Ilustración \\
\hline Tomo I No 2 & Velázquez & & E. de O. & & $3 \mathrm{pp}$ & $1^{\mathrm{a}}$ & NO & NO & $\mathrm{NO}$ \\
\hline Tomo I No 1 & Velázquez & & E. de O. & & $21 / 2 \mathrm{pp}$. & Interior & SÍ & SÍ & NO \\
\hline Tomo I No 3 & Juan de Herrera & & E. de O. & & $11 / 2 \mathrm{pp}$. & Interior & $\mathrm{NO}$ & SÍ & $\mathrm{NO}$ \\
\hline Tomo I No 5 & Calderón & & E. de O. & & $31 / 4 \mathrm{pp}$. & $1^{\mathrm{a}}$ & $\mathrm{NO}$ & Sí & NO \\
\hline Tomo I No 11 & D. José Álvarez & & E. de O. & & $2 \mathrm{l} / 2 \mathrm{pp}$ & $1^{a}$ & $\mathrm{NO}$ & Sí & $\mathrm{NO}$ \\
\hline Tomo I No 12 & D. Juan de Villanueva & & E. de $\mathrm{O}$, & & $3 / 4$ p. & Interior & NO & SÍ & NO \\
\hline Tomo I No 14 & $\begin{array}{l}\text { D. Francisco Martínez } \\
\text { de la Rosa }\end{array}$ & $\begin{array}{l}\text { Galería de Inje- } \\
\text { nios Contem- } \\
\text { poráneos }\end{array}$ & E. de O. & Literatura & 3 pp. & $1^{a}$ & NO & Sí & $\mathrm{NO}$ \\
\hline Tomo I No 14 & Murillo & & E. de O. & & $11 / 2 \mathrm{pp}$ & Interior & NO & $\mathrm{NO}$ & SÍ \\
\hline Tomo I No 15 & $\begin{array}{l}\text { D. Ángel de Saavedra, } \\
\text { duque de Rivas }\end{array}$ & $\begin{array}{l}\text { Galería de Inje- } \\
\text { nios Contem- } \\
\text { poráneos }\end{array}$ & E. de O. & Literatura & $3 \mathrm{pp}$ & Interior & NO & SÍ & $\mathrm{NO}$ \\
\hline Tomo I No 17 & $\begin{array}{l}\text { D. Juan Nicasio Ga } \\
\text { llego }\end{array}$ & $\begin{array}{l}\text { Galería de Inje- } \\
\text { nios Contem- } \\
\text { poráneos }\end{array}$ & F. V. M. & Literatura & 4 pp. & $1^{a}$ & NO & Sí & NO \\
\hline Tomo I No 19 & Bartolomé Pinelli & /Necrología & V. de C. & & $1 \mathrm{l} / 2 \mathrm{pp}$ & Interior & NO & $\mathrm{NO}$ & NO \\
\hline Tomo I No 22 & $\begin{array}{l}\text { D. Telesforo de True } \\
\text { ba Cosío }\end{array}$ & $\begin{array}{l}\text { Galería de Inje- } \\
\text { nios Contem- } \\
\text { poráneos }\end{array}$ & E. de O. & & $21 / 4 \mathrm{pp}$ & Interior & $\mathrm{NO}$ & $\mathrm{NO}$ & $\mathrm{NO}$ \\
\hline Tomo I No 23 & Fernando de Herrera & Noticias de & & & $1 / 2 \mathrm{p}$ & Interior & $\mathrm{NO}$ & $\mathrm{NO}$ & $\mathrm{NO}$ \\
\hline Tomo I No 25 & D. Alonso de Ercilla & & E. de O. & & $3 / 4 \mathrm{p}$ & Interior & $\mathrm{NO}$ & SÍ & $\mathrm{NO}$ \\
\hline Tomo II No 1 & $\begin{array}{l}\text { D. Manuel Bretón de } \\
\text { los Herreros }\end{array}$ & $\begin{array}{l}\text { Galería de Inje- } \\
\text { nios Contem- } \\
\text { poráneos }\end{array}$ & E. de O. & Literatura & $31 / 2 \mathrm{pp}$ & $1^{a}$ & NO & $\mathrm{NO}$ & $\mathrm{NO}$ \\
\hline
\end{tabular}




\begin{tabular}{|c|c|c|c|c|c|c|c|c|c|}
\hline Número & Título & Ante/subtítulo & Autor & Sección & Extensión & Posición & Seriada & Retrato & Ilustración \\
\hline Tomo II No 4 & $\begin{array}{l}\text { D. Manuel José Quin- } \\
\text { tana }\end{array}$ & \begin{tabular}{|l|} 
Galería de In- \\
genios Con- \\
temporáneos
\end{tabular} & E. de O. & Literatura & $13 / 4 \mathrm{pp}$ & $1^{a}$ & NO & NO & NO \\
\hline Tomo II No 5 & David Teniers & & P. de M. & & $11 / 2 \mathrm{pp}$ & $1^{a}$ & $\mathrm{NO}$ & $\mathrm{NO}$ & NO \\
\hline Tomo II No 5 & El barón Gros & & E. de O. & Necrología & $2 \mathrm{pp}$ & Interior & NO & $\mathrm{NO}$ & $\mathrm{NO}$ \\
\hline Tomo II No 6 & Henrick Wergeland & $\begin{array}{l}\text { Noticia sobre } \\
\text { las vida y obras } \\
\text { de }\end{array}$ & E. de O. & $\begin{array}{l}\text { Literatura } \\
\text { estranjera }\end{array}$ & $3 \mathrm{pp}$ & Interior & $\mathrm{NO}$ & $\mathrm{NO}$ & NO \\
\hline Tomo II No 13 & $\begin{array}{l}\text { Leonardo De Vinci, } \\
\text { pintor florentino }\end{array}$ & & & $\begin{array}{l}\text { Historia del } \\
\text { Arte }\end{array}$ & $33 / 4 \mathrm{pp}$. & & Sí & $\mathrm{NO}$ & NO \\
\hline Tomo II No 13 & Washington y Bolívar & & $\begin{array}{l}\text { Th. } \\
\text { Farmer }\end{array}$ & Historia & $11 / 4 \mathrm{pp}$. & Interior & $\mathrm{NO}$ & NO & NO \\
\hline Tomo II No 14 & Lope de Vega & & E. de O. & & $33 / 4 \mathrm{pp}$. & Interior & NO & NO & NO \\
\hline Tomo II No 14 & Paganiniw & & S. M. & & $11 / 4 \mathrm{pp}$ & $\begin{array}{l}\text { Penúl- } \\
\text { t i m a - } \\
\text { última }\end{array}$ & NO & $\mathrm{NO}$ & NO \\
\hline Tomo II No 16 & Bellini & & S. M. & & $21 / 2 \mathrm{pp}$ & $\begin{array}{l}\text { Interior- } \\
\text { última }\end{array}$ & $\mathrm{NO}$ & $\mathrm{NO}$ & NO \\
\hline Tomo II No 17 & $\begin{array}{l}\text { Doña Concepción } \\
\text { Rodríguez }\end{array}$ & Biografía & A. & & $31 / 2 \mathrm{pp}$ & $1^{\mathrm{a}}$ & $\mathrm{NO}$ & Sí & NO \\
\hline Tomo II No 19 & $\begin{array}{l}\text { Leonardo de Vinci, } \\
\text { pintor florentino }\end{array}$ & & & $\begin{array}{l}\text { Historia del } \\
\text { arte }\end{array}$ & $3 \mathrm{pp}$ & Interior & Sí & $\mathrm{NO}$ & NO \\
\hline Tomo II No 22 & $\begin{array}{l}\text { D. Francisco de Goya, } \\
\text { pintor }\end{array}$ & Biografía de & \begin{tabular}{|l|} 
V. \\
Carderera
\end{tabular} & & $3 \mathrm{pp}$ & $1^{a}$ & $\mathrm{NO}$ & Sí & NO \\
\hline Tomo II No 24 & D. Vicente López & $\begin{array}{l}\text { Galería de In- } \\
\text { genios Con- } \\
\text { temporáneos }\end{array}$ & J. N. G. & Literatura & $31 / 2 \mathrm{pp}$ & $1^{a}$ & $\mathrm{NO}$ & Sí & NO \\
\hline Tomo II No 4 & $\begin{array}{l}\text { Visión de S. Pedro } \\
\text { Velasco, por Zurbarán }\end{array}$ & & P. de M. & & $11 / 2 \mathrm{pp}$ & Interior & $\mathrm{NO}$ & NO & Sí \\
\hline Tomo II No 26 & Don Alberto Lista & $\begin{array}{l}\text { Galería de Inge- } \\
\text { nios Contem- } \\
\text { poráneos }\end{array}$ & E. de O. & Literatura & $31 / 4$ pp. & $1^{\mathrm{a}}$ & NO & Sí & NO \\
\hline Tomo II. No 26 & D. José de Madrazo & $\begin{array}{l}\text { Galería de Inge- } \\
\text { nios Contem- } \\
\text { poráneos }\end{array}$ & V.C. & Literatura & 4 pp. & Interior & NO & Sí & NO \\
\hline Tomo III No 1 & D. Isidro Velázquez & $\begin{array}{l}\text { Galería de Inge- } \\
\text { nios Contem- } \\
\text { poráneos }\end{array}$ & & Literatura & $31 / 2 \mathrm{pp}$ & Interior & NO & Sí & NO \\
\hline Tomo III No 2 & $\begin{array}{l}\text { Noticias de poetas có- } \\
\text { micos sevillanos }\end{array}$ & & $\begin{array}{l}\text { J. Colom y } \\
\text { Colom }\end{array}$ & & $21 / 4 \mathrm{pp}$ & $1^{\mathrm{a}}$ & NO & NO & NO \\
\hline Tomo III No 3 & $\begin{array}{l}\text { D. Juan Antonio de } \\
\text { Ribera }\end{array}$ & $\begin{array}{l}\text { Galería de Inge- } \\
\text { nios Contem- } \\
\text { poráneos }\end{array}$ & F.M. & Bellas Artes & $21 / 4$ pp. & $1^{\mathrm{a}}$ & NO & SÍ & NO \\
\hline Tomo III No 4 & $\begin{array}{l}\text { Don José Rivelles y } \\
\text { Helip }\end{array}$ & $\begin{array}{l}\text { Galería de Inge- } \\
\text { nios Contem- } \\
\text { poráneos }\end{array}$ & $\begin{array}{l}\text { L. de U. } \\
\text { yR. }\end{array}$ & Bellas Artes & $23 / 4 \mathrm{pp}$. & $1^{\mathrm{a}}$ & NO & Sí & NO \\
\hline Tomo III No 5 & Haendel & Biografía & & Bellas Artes & 3 pp. & $1^{\mathrm{a}}$ & NO & NO & NO \\
\hline Tomo III No 6 & Beaumont y Fletcher & $\begin{array}{l}\text { Noticias de } \\
\text { poetas dramá- } \\
\text { ticos ingleses }\end{array}$ & & & $13 / 4 \mathrm{pp}$ & Interior & $\mathrm{NO}$ & NO & NO \\
\hline
\end{tabular}




\begin{tabular}{|c|c|c|c|c|c|c|c|c|c|}
\hline Número & Título & Ante/subtítulo & Autor & Sección & Extensión & Posición & Seriada & Retrato & Ilustración \\
\hline Tomo III No 7 & El general Bourgoyne & $\begin{array}{l}\text { Noticias de } \\
\text { poetas dramá- } \\
\text { ticos ingleses }\end{array}$ & T. E. & & 4 pp. & Interior & NO & NO & NO \\
\hline Tomo III No 8 & Necrología & & S. de M. & & $1 \mathrm{p}$. & $1^{\mathrm{a}}$ & NO & NO & NO \\
\hline Tomo III No 8 & Pedro Pablo Rubens & Biografía & & Bellas Artes & $3 \mathrm{pp}$ & Interior & NO & NO & NO \\
\hline Tomo III No 10 & Nicolás Pussino & & M. P. & Bellas Artes & $11 / 2 \mathrm{pp}$ & $1^{\mathrm{a}}$ & NO & NO & NO \\
\hline Tomo III No 11 & $\begin{array}{l}\text { D. Antonio García Gu- } \\
\text { tiérrez }\end{array}$ & $\begin{array}{l}\text { Galería de Inge- } \\
\text { nios Contem- } \\
\text { poráneos }\end{array}$ & E. de O. & Literatura & $21 / 2 \mathrm{pp}$. & $1^{\mathrm{a}}$ & NO & Sí & NO \\
\hline Tomo III No 12 & $\begin{array}{l}\text { Don Santiago de Ma- } \\
\text { sarnau }\end{array}$ & $\begin{array}{l}\text { Galería de Inge- } \\
\text { nios Contem- } \\
\text { poráneos }\end{array}$ & P. de M. & Bellas Artes & 23/4 pp. & $1^{\mathrm{a}}$ & NO & Sí & NO \\
\hline Tomo III No 12 & $\begin{array}{l}\text { Don Esteban de Ágre- } \\
\text { da }\end{array}$ & $\begin{array}{l}\text { Galería de Inge- } \\
\text { nios Contem- } \\
\text { poráneos }\end{array}$ & E. de O. & Bellas Artes & $11 / 4 \mathrm{p}$ & $\begin{array}{l}\text { Penúl- } \\
\text { ti ma - } \\
\text { última }\end{array}$ & NO & Sí & NO \\
\hline Tomo III No 13 & Don Ramón Carnicer & $\begin{array}{l}\text { Galería de Inge- } \\
\text { nios Contem- } \\
\text { poráneos }\end{array}$ & E. de O. & Bellas Artes & $11 / 4$ pp. & $1^{\mathrm{a}}$ & NO & Sí & NO \\
\hline Tomo III No 13 & $\begin{array}{l}\text { D. Juan Carreño de Mi- } \\
\text { randa }\end{array}$ & & V.C. & Nobles Artes & $11 / 2 \mathrm{pp}$. & Interior & NO & NO & NO \\
\hline Tomo III No 13 & $\begin{array}{l}\text { D. Juan Miguel de In- } \\
\text { clán }\end{array}$ & $\begin{array}{l}\text { Galería de Inge- } \\
\text { nios Contem- } \\
\text { poráneos }\end{array}$ & E. de O. & Bellas Artes & $11 / 4$ pp. & Interior & NO & Sí & NO \\
\hline Tomo III No 13 & $\begin{array}{l}\text { D. Custodio Teodoro } \\
\text { Moreno }\end{array}$ & $\begin{array}{l}\text { Galería de Inge- } \\
\text { nios Contem- } \\
\text { poráneos }\end{array}$ & E.de O. & & $2 \mathrm{pp}$ & Interior & NO & Sí & NO \\
\hline
\end{tabular}

Fuente: elaboración propia

\section{Referencias bibliográficas}

Anónimo (1865, 29 de enero). "Autógrafos de hombres célebres". En: El Museo Universal, Madrid.

Alborg, J. L. (1980). Historia de la literatura española. En: El Romanticismo, Tomo IV. Madrid: Gredos.

Comellas, J. L. (1988) Historia de España Contemporánea. Madrid: Rialp.

Edel, L. (1984). Principia Biographica. Nueva York: NortonECompany.

Genette, G. (1998). Nuevo discurso del relato. Madrid: Cátedra.

Gómez, B. (2006). Los textos biográficos en las cinco principales revistas ilustradas españolas del siglo XIX. Aproximación a los orígenes de un género periodístico, tesis doctoral. Pamplona: Facultad de Comunicación, Universidad de Navarra.
Guarner, L. (1953). El Europeo (Barcelona, 1823-1824). Madrid: Instituto "Miguel de Cervantes" del Consejo Superior de Investigaciones Científicas.

López Hidalgo, A. (1998). "La necrológica como género periodístico". En: Ámbitos. Revista Andaluza de Comunicación, $\mathrm{N}^{\circ} 1$, pp. 89-106.

Randolph, D. A. (1966). Eugenio de Ochoa y el romanticismo español. Los Ángeles: University of California publications in modern philology, Vol. 75, University of California Press.

Rosendo, B. (1999). El perfil como género periodístico, tesis doctoral, Pamplona: Facultad de Comunicación, Universidad de Navarra.

Sánchez, J. F. y López Pan, F. (1998). "Tipologías de géneros periodísticos en España. Hacia un nuevo paradigma". En: Comunicación y Estudios Universitarios, monográfico: Los géneros periodísticos en los medios 
de comunicación impresos, ¿̇ocaso o vigencia?, No 8, pp. 15-35.

Sánchez Aranda, J. J. y Barrera, C. (1992). Historia del periodismo español. Desde sus orígenes hasta 1975 , Pamplona: Eunsa.

Sánchez Aranda, J. J. (1994). Desde los orígenes del periodismo hasta la edad dorada de la prensa, Pamplona: Departamento de Comunicación Pública, serie "Notas de trabajo", No 6.

Seoane, M. C. (1977). Oratoria y periodismo en la España del siglo XIX, Valencia: Castalia.

Seoane, M. C. (1983). Historia del periodismo en España. 2. El siglo XIX, Madrid: Alianza.
Simón Díaz, J. (1946). El Artista (Madrid 1835-1836), Madrid: Instituto "Nicolás Antonio" del Consejo Superior de Investigaciones Científicas.

Tolles, F. B. (1996). "The biographer's craft". En: Eisenstadt, A. S. (ed.): The craft of american history, vol. II, Nueva York: Harper Torchbooks, pp. 71-83.

Vidal, D. (2005). El malson de Chandos. La crisi acadèmica $i$ professional del periodisme des de la crisi postmoderna de la paraula. Castellón de la Plana: Publicacions de la Universitat Jaume I.

Winslow, D. J. (1995). Life-writing, a glossary of terms in biography, autobiography and related forms, Honolulu: University of Hawai'i Press. 